\title{
THE PREVENTION OF SHOULDER PAIN AND CONTRACTURE IN THE ACUTE TETRAPLEGIA PATIENT
}

\author{
By Judith A. Scott, S.R.N. and William H. Donovan, M.D. \\ Royal Perth (Rehabilitation) Hospital, Shenton Park, Western Australia
}

\begin{abstract}
Distress and concern over the development of painful frozen shoulders in several tetraplegic patients prompted a change in posturing at the Royal Perth (Rehabilitation) Hospital, Spinal Unit, Perth, Western Australia that has resulted in elimination of this complication. The method of positioning the arms in the supine and side lying positions is described and the application of the method in four of 15 patients is presented.
\end{abstract}

Key words: Acute tetraplegia; Shoulder pain; Contracture prevention.

\section{Introduction}

THE development of contractures about the shoulder joint is a recognised complication that may occur in patients with neurological disorders (Ellwood, I97I), even in conscious patients. When the muscle balance about the shoulder is altered by paralysis, spasticity, inflammation or trauma, the ability to abduct the arm may be compromised since the deltoid, the biceps and the muscles of the rotator cuff must contract as a co-ordinated 'force couple' so that the humeral head is depressed as the arm is raised (Lippman, I95I; Watson-Jones, I955; Donovan, I974). If abduction of the affected $\operatorname{arm}(\mathrm{s})$ is not carried out either actively or passively, the muscles which are in their lengthened positions during abduction (e.g. the pectoralis major and minor and latissimus dorsi) will shorten. Further, as the normal redundancy of the capsule of the glenohumeral joint becomes lost, the picture of 'frozen shoulder' or 'adhesive capsulitis' is reached (Killoran, I968). Once this occurs, future efforts to restore full abduction range will meet with resistance and pain as the shortened fibres of muscle and tendon are stretched (Lippmann, I95I; Turek, 1967).

It is particularly important that this complication is not allowed to develop in tetraplegic patients, particularly since 'trick movements' occurring at the shoulder, may have to compensate for poor or absent control of distal joints and full range of motion in abduction and external rotation is necessary to reach optimum levels of independence in activities of daily living.

Despite this, the authors were struck by the paucity of literature that dealt with the prevention of this complication particularly since it was so difficult to treat once developed, and seemed to be rather a common occurrence in many spinal cord injury centres when the subject was discussed informally among colleagues.

This paper describes a method which has effectively prevented the occurrence of adhesive capsulitis in I 5 patients and consists mainly of diligent adherence to the techniques of posturing described herein which are carried out by the nursing staff at the Royal Perth (Rehabilitation) Hospital in Perth, Western Australia. 


\section{Method}

Prior to implementing posturing changes in January 1978 at this Spinal Unit, patients were nursed with their arms at their side when supine and when in the lateral position, the uppermost arm was placed on one pillow next to the chest. Patients frequently experienced shoulder pain, particularly when any sort of pressure was applied to the bony prominence of the shoulder. Despite the fact that passive movements were carried out twice daily during the acute phase of hospitalisation, some patients experienced severe pain and stiffness which necessitated frequent analgesia and reposturing. Occasionally the situation became chronic and in the year prior to the initiation of this study, two patients went on to develop chronically painful stiff shoulders.

It was decided to experiment with a change of posturing of the patients' arms and shoulders in the way described below, to see if it would make any difference in the frequency with which shoulder pain developed. Now, when the patient is postured supine, his shoulders are abducted to $90^{\circ}$ and are slightly extended. Both arms are supported on pillows which are placed on specially made boards (arm boards) that slip in under the mattress. It is very important to ensure that the arms remain abducted, level with the trunk, and extended at the elbow (Fig. I). If this is not maintained, one finds that the flexion of the elbow and internal rotation of the shoulder causes it to adduct somewhat. As an adjunct, whilst the patient is supine, it is also important to carry out twice daily passive movements bringing the arm above the patient's head into full abduction and external rotation approximately Io times (Fig. 2).

It is well recognised that acute tetraplegic patients should be turned and re-postured every 2 hours, from side to back to side. In the past, it was found that whilst the patient was postured on his side the shoulder pain was typically worse. Now when the patient is postured on his side, he has an axillary pillow placed under his chest. This helps maintain correct alignment and also relieves some of the pressure borne by the acromion process and head of the humerus. The uppermost arm is extended and abducted about $45^{\circ}$. This shoulder becomes slightly

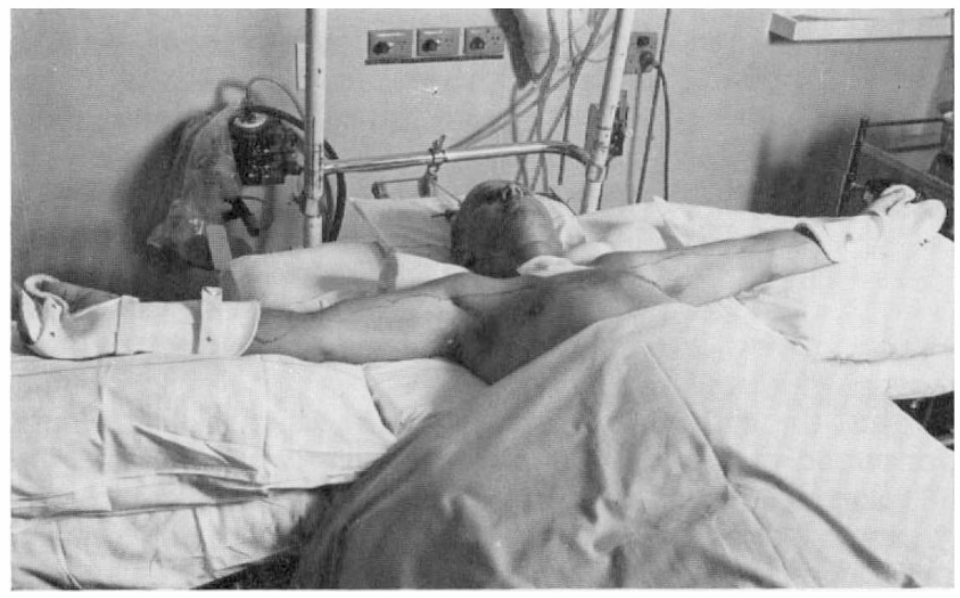

FIG. I

37-year-old male with $\mathrm{C}_{5}$ quadriplegia due to a surfing accident. Arms shown in $90^{\circ}$ abducted position. 


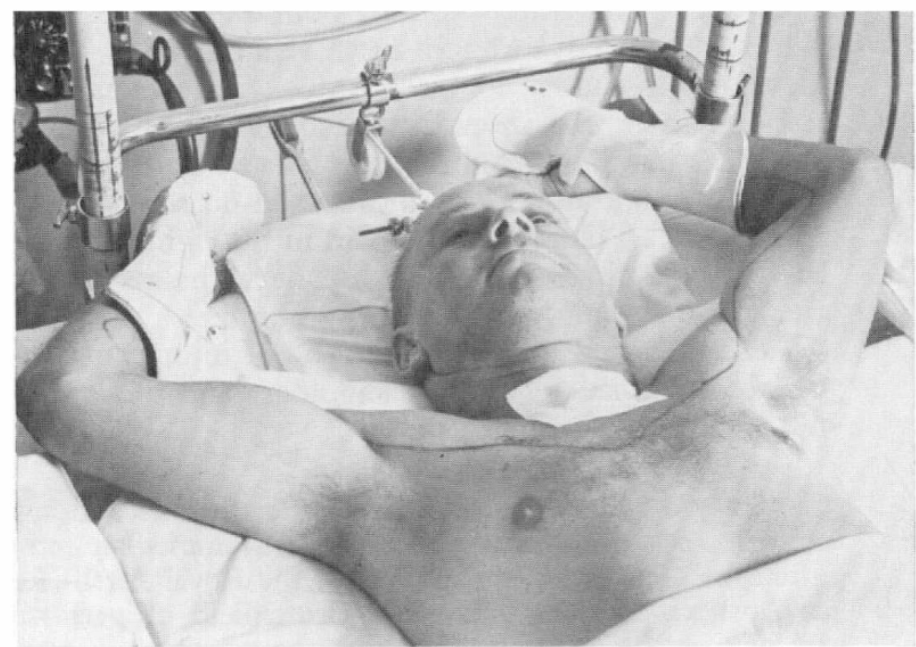

FIG. 2

Arms positioned in external rotation and abduction beyond $90^{\circ}$ at conclusion of massive movement by physiotherapist, prior to resumption of position shown in Fig. I.

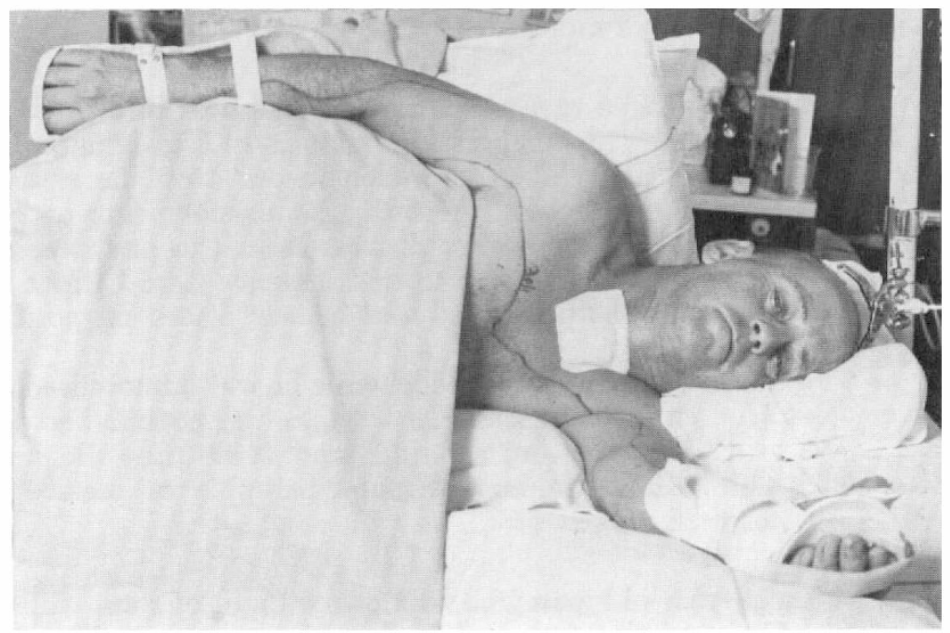

FIG. 3

Patient positioned on left side. Position of axillary pillow under left chest and position of right arm in extended position are shown.

protracted as the arm itself is positioned on a pillow that is placed behind the patient (Fig. 3). When carried out properly, this posturing technique will not interfere with the proper posturing of the neck which is dictated by the nature of the cervical injury.

\section{Results}

Since implementing these posture changes in January 1978, the authors have observed I5 patients with acute cervical injuries. Of these, two patients subsequently recovered and were discharged home, ambulant and with very minor upper 
limb weakness. They did not have any shoulder pain or stiffness. The remaining I3 tetraplegic patients continued through their rehabilitation programme and none of them has developed shoulder contractures or 'adhesive capsulitis'. Three had marked spasticity involving the shoulder adductors. Two patients had slight transient shoulder pain during their rehabilitation phase but this was not severe, it did not result in reduced range of motion, and caused no reduction in their programme. One patient (Case 4) had moderate pain in his right shoulder which had been present well before his spinal cord injury but nevertheless had $120^{\circ}$ of painfree abduction range at the completion of his programme:

Four cases are described and illustrate the type of injury sustained and how their treatment was accompanied by lack of shoulder pain during their hospital stay:

Case r. E.L. is a 25-year-old male who dived into the surf and sustained a $\mathrm{C}_{5}$ compression fracture with a retrolisthesis of $\mathrm{C}_{5}$ on $\mathrm{C} 6$, with immediate tetraplegia at $\mathrm{C}_{5}$ level. He was admitted directly to the Spinal Unit at the Royal Perth (Rehabilitation) Hospital in Western Australia and was nursed in Crutchfield calipers with Io lbs of traction, for a period of 6 weeks. During this time, he was nursed with his arms in abduction and extension and at no time did he complain of any acute shoulder pain. At least twice a day his arms were raised above his head for short periods repetitively. E.L. maintained supple, pain-free shoulder movements throughout his period of cervical immobilisation. After he was allowed out of bed, at no stage did he complain of shoulder pain or manifest reduced range of motion.

Case 2. D.L. is a 27-year-old male who dived from a boat into shallow water and suffered a cervical injury resulting in compression fractures of $\mathrm{C}_{3}, \mathrm{C}_{4}$ and $\mathrm{C}_{5}$ with complete motor loss below $\mathrm{C}_{4}$. After direct admission to our Unit, he was managed in Crutchfield calipers with 7 lbs of traction. Within 24 hours following his admission to the Spinal Unit, he suffered acute respiratory distress related to previous inhalation of sea water. He was intubated and transferred to the Intensive Care Unit at Royal Perth Hospital where a tracheostomy was performed and he was placed on positive pressure ventilation.

His general condition became stable. All the while he was immobilised, i.e. 6 weeks both in the Intensive Care Unit and at the Spinal Unit, he was postured according to the new regime with his arms adbucted and extended and at no time did he experience unremitting shoulder pain. His shoulders remained supple to passive movements throughout his entire hospitalisation.

Case 3. J.M. is a 58-year-old man who fell down a flight of steps whilst under the influence of alcohol. On admission to hospital a head injury was presumed because he was stuporous and could not give a history at that time. The next day when more alert, he complained of neck pain and it was discovered that he was in fact incompletely tetraplegic at $\mathrm{C}_{5}$ level and unable to void urine. X-rays revealed no fractures but did show severe disc narrowing at $\mathrm{C}_{5}, \mathrm{C} 6$ and $\mathrm{C}_{7}$ with considerable spondylosis. Flexion/ extension $\mathrm{X}$-rays showed slight opening anteriorly at the disc space at $\mathrm{C} 4 / 5$ levels. This man had sustained a hyperextension injury and developed a typical central cord type syndrome accompanied by quite severe spasm of his limbs. He was nursed in a cervical collar in slight flexion. Routine acute nursing management was carried out, and once again the arm posturing had particular attention paid to it. At first it was difficult to maintain the arms in abduction and extension, due to spasms but with good nursing, perseverance, and antispasticity medication, adequate positioning was achieved by restraining the arms on the side pillows whilst the patient was postured supine and when repositioned on to his side, the previously mentioned posture was carried out as well. The patient did not complain of severe shoulder pain and it was noted that the shoulder 
stiffness which often develops in patients with central cord syndrome, was markedly reduced by the posturing. Once this patient was mobilised, he commenced the rehabilitation programme and improved to the extent where he is now ambulant and has fair to good motor recovery of the upper extremity proximal muscles, but only poor to fair finger function. It is pleasing to note that he does not suffer any shoulder pain or stiffness.

Case 4. G.A. is a 67-year-old alcoholic with a past history of seizures who collapsed and lost consciousness suddenly after commencing his morning flagon of wine. It was not known if he had a seizure, but when he awoke he was unable to move his arms or legs and complained of pain in his neck and left arm. Examination that afternoon revealed a

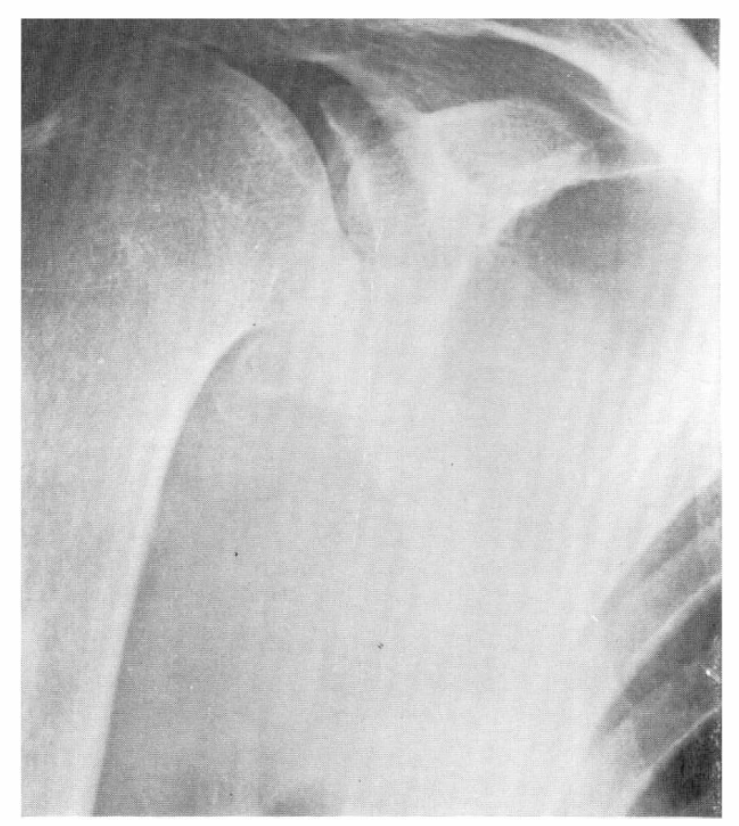

FIG. 4

X-ray of patient No. 4's right shoulder, showing marked degenerative changes and healed fracture of the anatomical head of the humerus.

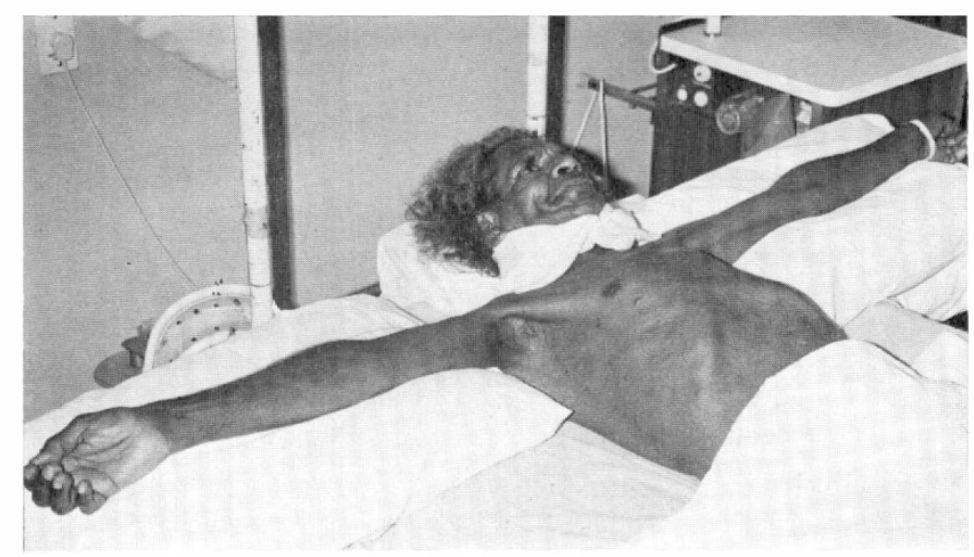

FIG. 5

Patient No. 4 positioned with both arms in pain free $90^{\circ}$ abduction. 
$\mathrm{C}_{4}$ motor and $\mathrm{C}_{5}$ sensory level with sparing of patterns of flexion and extension movement in the legs, along with the sensations of deep pressure and light touch. Sacral sensory and motor sparing also was noted. X-rays of his spine revealed a fracture of the spinous process of $\mathrm{C}_{4}$ and slight retrolisthesis of a congenital $\mathrm{C}_{4} / 5$ block vertebra. $\mathrm{X}$-rays of a painful right shoulder, revealed an old healed fracture of the neck of the humerus and severe degenerative changes (Fig. 4).

It was felt this man also sustained a hyperextension injury producing a central cord syndrome. He was placed in a cervical collar in flexion and allowed up in a wheelchair after 3 weeks. Throughout his hospital stay however, whilst in bed, he was postured in the fashion described for patient No. 3. Full range of motion was maintained in the left shoulder while the right shoulder improved from $60^{\circ}$ abduction to $120^{\circ}$ of pain free motion. His neurological recovery in the upper extremities did not improve beyond grade I (trace) in both deltoids and biceps, yet his shoulders remained pain free (Fig. 5).

\section{Discussion}

The importance of proper posturing of patients with neurological disorders has been recognised for some time. The shoulder, wrist, hip and ankle have received particular emphasis in standard texts (Ellwood, I97I). Surprisingly little however has appeared in the literature, even in Journals dealing with spinal-cord injured patients. Nichols et al. (1979) reported an incidence of shoulder pain in $5 \mathrm{I} \cdot 4$ per cent of spinal cord injured patients surveyed by the Spinal Injuries Association in Great Britain. The pain was severe enough to interfere with sleep in 42.6 per cent. The incidence increased with age yet remained higher than the estimated incidence in the general population for all age groups. Braun et al. (I97I) discussed the importance of prevention of painful shoulder contractures in stroke patients, using physiotherapy and described a method of surgical correction of developed contractures, consisting of resecting the tendon of the subscapularis. A search of the literature failed to turn up any articles describing a method of prevention or treatment of this problem in patients with spinal cord injury even though some tetraplegic patients may have severe spasticity of the upper extremities on a par with patients who have sustained a cerebrovascular accident. The method of posturing described above has been found to be successful in preventing a problem which, once developed, is difficult to treat. It requires extreme diligence on the part of the nursing staff, to ensure that the posturing is maintained at all times. Medical support and encouragement to the patient and family is also important so that any misgivings about being placed in the 'crucifixion position' can be allayed, as the treatment causes less discomfort than the complication that it prevents. It may well be that the incidence of shoulder pain that Nichols et al. (1979) found to be so high was in part due to contractures which developed during the acute phase of rehabilitation rather than related to the act of self propelling a wheelchair as those authors suspected. It is also important to educate the patients to continue the extension abduction posturing of the arms once they are in the rehabilitation phase of their programmes for at least 4 to 6 weeks, or at least until they are carrying out activities of daily living such as dressing or grooming when they will be using their arms sufficiently to prevent contractures from developing.

The authors recognise that this was not a controlled study with random patient selection. Rather it compares the patients treated against those treated in the past. The complete absence of 'frozen shoulder' as well as disabling shoulder pain, since the beginning of the treatment is noteworthy however. Therefore, this method of management will be continued for a longer trial at the Royal Perth (Rehabilitation) Hospital. 


\section{SUMMARY}

A method of preventing shoulder contractures from developing in patients with acute tetraplegia is described. Fifteen patients, including three with marked upper extremity spasticity were treated in this fashion and none developed adhesive capsulitis.

\section{RÉSUMÉ}

La méthode suivante est employée pour empêcher les contractions musculaires de l'épaule chez les malades atteint de quadraplegie aigue. Quinze malades dont trois souffraien de paralysie intense au haut de l'épaule ont été traités de cette façon et aucun d'eux n'a développe d'inflammation tenace.

\section{ZUSAMMENFASSUNG}

Eine Methode zur Vermeidung von Schulterkontrakturen in Tetraplegikern wird beschrieben. I5 Patienten werden beschrieben, unter ihnen 3 mit erheblicher Spastizität, die mit dieser Methode behandelt wurden. Keiner entwickelte adhesive Capsulitis.

\section{REFERENCES}

Braun, R. M., West, F. \& Mooney, V. et al. (I97I). Treatment of the painful shoulder contracture in the stroke patient. F. Bone Foint Surg., 53A, I307-1312.

Donovan, W. H. \& KRAFT, G. H. (I974). Rotator cuff tear versus suprascapular nerve injury: a problem in differential diagnosis. Arch. Phys. Med. Rehabil., 55, 424-428.

Ellwood, P. M. Jr. (I97I). In Handbook of Physical Medicine and Rehabilitation, pp. 463472. W. B. Saunders, Philadelphia.

Killoran, P. T., MARCove, R. C. \& Freiberger, R. H. (I968). Shoulder arthrography. Amer. F. Roentgenol. Radium Ther. Nucl. Med., 103, 658-668.

LippmanN, R. K. (I95I). The frozen shoulder. S. Clin. North Am., 31, 367-383.

Nichols, P. J. R., NoRman, P. A. \& EnNIS, J. R. (I979). Wheelchair users shoulder? Scand. F. Rehab. Med., II, 29-32.

Turk, S. L. (1967). Orthopaedics-Principles and their Application, pp. 556-559. J. B. Lippincott, Philadelphia.

Watson-Jones, Sir R. (I955). Fractures and foint Injuries, 4th ed. Vol. 2. pp. 452-455. Williams and Wilkins, Baltimore. 